\title{
Age, time from injury to surgery and hop performance after primary ACLR affect the risk of contralateral ACLR
}

\author{
Riccardo Cristiani $^{1,2}$ (D) Magnus Forssblad ${ }^{1} \cdot$ Gunnar Edman $^{1} \cdot$ Karl Eriksson $^{3} \cdot$ Anders Stålman $^{1,2}$
}

Received: 2 August 2021 / Accepted: 27 September 2021 / Published online: 7 October 2021

(c) The Author(s) 2021

\begin{abstract}
Purpose To evaluate factors affecting the risk of contralateral anterior cruciate ligament reconstruction (ACLR) within 5 years of primary ACLR.

Methods Primary ACLRs performed at Capio Artro Clinic, Stockholm, Sweden, during the period 2005-2014, were reviewed. The outcome of the study was the occurrence of contralateral ACLR within 5 years of primary ACLR. Univariable and multivariable logistic regression analyses were employed to identify preoperative [age, gender, body mass index (BMI), time from injury to surgery, pre-injury Tegner activity level], intraoperative [graft type, medial meniscus (MM) and lateral meniscus (LM) resection or repair, cartilage injury] and postoperative [limb symmetry index (LSI) for quadriceps and hamstring strength and single-leg-hop test performance at 6 months] risk factors for contralateral ACLR.

Results A total of 5393 patients who underwent primary ACLR were included. The incidence of contralateral ACLR within 5 years was $4.7 \%$. Univariable analysis revealed that age $\geq 25$ years, BMI $\geq 25 \mathrm{~kg} / \mathrm{m}^{2}$, time from injury to surgery $\geq 12$ months and the presence of a cartilage injury reduced the odds, whereas female gender, pre-injury Tegner activity level $\geq 6$, quadriceps and hamstring strength and a single-leg-hop test LSI of $\geq 90 \%$ increased the odds of contralateral ACLR. Multivariable analysis showed that the risk of contralateral ACLR was significantly affected only from age $\geq 25$ years (OR 0.40; 95\% CI $0.28-0.58 ; P<0.001)$, time from injury to surgery $\geq 12$ months (OR $0.48 ; 95 \% \mathrm{CI} 0.30-0.75 ; P=0.001$ ) and a single-leg-hop test LSI of $\geq 90 \%$ (OR $1.56 ; 95 \%$ CI 1.04-2.34; $P=0.03$ ).

Conclusion Older age ( $\geq 25$ years) and delayed primary ACLR ( $\geq 12$ months) reduced the odds, whereas a symmetrical (LSI $\geq 90 \%$ ) 6-month single-leg-hop test increased the odds of contralateral ACLR within 5 years of primary ACLR. Knowledge of the factors affecting the risk of contralateral ACLR is important when it comes to the appropriate counselling for primary ACLR. Patients should be advised regarding factors affecting the risk of contralateral ACLR.
\end{abstract}

Level of evidence Level III.

Keywords Anterior cruciate ligament · ACL · Contralateral · Age · Graft · Meniscus · Cartilage · Quadriceps strength · Limb symmetry index

Riccardo Cristiani

riccardo.cristiani87@gmail.com

1 Department of Molecular Medicine and Surgery, Stockholm Sports Trauma Research Center, Karolinska Institutet, Stockholm, Sweden

2 Capio Artro Clinic, FIFA Medical Centre of Excellence, Sophiahemmet Hospital, Valhallavägen 91, 11486 Stockholm, Sweden

3 Department of Orthopaedics, Stockholm South Hospital, Karolinska Institutet, Stockholm, Sweden

\section{Introduction}

An anterior cruciate ligament (ACL) tear is a major knee injury which might have a serious impact on patients' quality of life. An ACL reconstruction (ACLR) is generally recommended for patients involved in cutting/ pivoting activities or in the event of functional instability [28]. Primary ACLR is successful in restoring knee laxity and improving subjective knee function $[7,8,11$, 15]. However, patients with an ACL-reconstructed knee run a greater risk of sustaining an ACL injury in either knee compared with individuals with a healthy knee [26]. In particular, the contralateral knee runs a higher risk 
compared with the ipsilateral knee at longer follow-ups [39]. Previous studies have reported rates of contralateral ACL injury ranging from 2 to $15 \%$ [2, 3, 20, 39], with this event typically occurring between 1 and 4 years after the primary ACLR [37, 39]. Several patients suffering a contralateral ACL injury may undergo ACLR. Data from the Swedish National Knee Ligament Registry [19] showed a contralateral ACLR rate of $3.8 \%$ at a 5-year follow-up after primary ACLR. Even though a recent study [12] reported that the results in terms of knee laxity and subjective knee function after contralateral ACLR are comparable to those after primary ACLR, contralateral ACLR remains a troublesome event for patients, as it requires the repeat of another long rehabilitation process.

A knowledge of the risk factors for contralateral ACLR is therefore important for clinicians when counselling patients undergoing primary ACLR. In addition, if some of these factors are modifiable, there would be the possibility to reduce the risk of this serious event.

There is evidence from several studies $[2,16,17,23$, $31,36]$ that younger age is an important risk factor for contralateral ACLR. However, the literature is scarce and inconsistent regarding the role of gender $[2,16,23,31$, $36]$, body mass index (BMI) [13, 23], time from injury to primary ACLR $[2,13]$ and the graft choice at primary ACLR [2, 23, 27]. Moreover, there is a lack of studies investigating the potential influence on the risk of contralateral ACLR of factors that are modifiable by rehabilitation, such as muscle strength and hop performance after primary ACLR.

The purpose of this study was to evaluate risk factors for contralateral ACLR within 5 years of primary ACLR. It was hypothesised that female gender, younger age, a high $(\geq 6)$ pre-injury Tegner activity level [33], the use of a bonepatellar tendon-bone (BPTB) autograft at the time of primary ACLR and a symmetrical (limb symmetry index [LSI] of $\geq 90 \%$ ) quadriceps strength and hop test performance 6 months after primary ACLR would be risk factors for contralateral ACLR within 5 years after the index surgery.

\section{Materials and methods}

Patient data were extracted from our clinic database. Patients registered for primary ACLR from 2 January 2005 to 7 March 2014 were assessed for eligibility. Only patients who underwent primary ACLR with a hamstring tendon (HT) or a BPTB autograft and had no concomitant ligament injuries were included.

Ethical approval for this study was obtained from the Regional Ethics Committee, Karolinska Institutet (Dnr 2016/1613-31/2).

\section{Surgical technique and rehabilitation}

A single-bundle technique was used for all primary ACLRs. Only patients who received an HT or a BPTB graft were included. The choice of the graft was made by the operating surgeon. Graft harvesting and fixation, femoral tunnel drilling as well as meniscal repair techniques have been described earlier [6, 8, 9]. Rehabilitation milestones have also been reported previously [6-9]. Patients were recommended to return to sport at the earliest 6 months postoperatively, depending on quadriceps and hamstring strength (LSI $\geq 90 \%$ ) and the results of the single-leg-hop test (LSI $\geq 90 \%$ ).

\section{Isokinetic strength and single-leg-hop test performance assessment}

The assessment of isokinetic strength and single-leg-hop test performance was made 6 months postoperatively. A standardized protocol was used. The Biodex System 3 (Biodex Medical Systems, Shirley, New York, USA) was used for testing. Isokinetic strength (quadriceps and hamstring) was tested in both knees at $90^{\circ} / \mathrm{sec}$ and in range of motion of $90^{\circ}-10^{\circ}$ of knee flexion. The test started always with the uninjured knee. Before the test, the patients warmed up using a stationary cycling ergometer at a low resistance for $10 \mathrm{~min}$. A verbal description of the test was given and patients were allowed to perform 2-3 practical trials before the test. A total of 5 maximum contractions (quadriceps and hamstring) with each leg were performed by the patients. The highest torque values for both quadriceps and hamstring were registered.

Hop performance was assessed with the single-leg-hop test $[6,10,35]$. Patients stood on one leg and were asked to jump straight as far as possible and land on the same leg. A stable landing was the criterion to consider the test successful. The test was repeated in case of early touchdown with the contralateral leg, loss of balance or in the event that the patient took additional hops after landing. A verbal description of the test was provided to the patients. Some practical trials were also allowed, until patients felt enough confident with the modality of the test. Three trials were performed for each leg. The uninjured leg was always tested first. The trial in which was obtained the best result for each leg was registered.

\section{Data sources}

Data were extracted from our clinic database. The preoperative factors evaluated were age, gender, body mass index (BMI), time from injury to primary ACLR and preinjury Tegner activity level [33]. Age was dichotomised 
into unbiased classes close to the median $(<25$ years or $\geq 25$ years). The BMI was dichotomised at $25 \mathrm{~kg} / \mathrm{m}^{2}$, since a BMI of $\geq 25$ is considered overweight [38]. Time from injury to primary ACLR was dichotomised into unbiased classes ( $<12$ months or $\geq 12$ months) close to the median. Finally, the pre-injury Tegner activity level was dichotomised as high $(\geq 6)$ or low $(<6)$. The intraoperative factors investigated were the type of graft (HT or BPTB autograft), medial meniscus (MM) resection, lateral meniscus (LM) resection, MM repair, LM repair and cartilage injury. The postoperative factors (6 months) included were isokinetic quadriceps and hamstring strength tests and the single-leg-hop test. The results of these tests were reported depending on the limb symmetry index (LSI) as symmetrical (LSI of $\geq 90 \%$ ) or asymmetrical (LSI of $<90 \%)[8,9,35]$.

\section{Outcome}

The outcome was the occurrence of contralateral ACLR within 5 years of primary ACLR. Patients who underwent contralateral ACLR at any institution in the country were identified through their unique Swedish personal identity number [22] in the Swedish National Knee Ligament Registry [34]. Follow-up started on the date of the index, primary ACLR and was up to 5 years (1827 days). Patients who underwent contralateral ACLR within this lapse of time were identified and included in the analysis.

\section{Statistical analysis}

Statistical analysis was performed using the Statistical Package for Social Sciences, SPSS (Version 25.0, IBM Corp., Armonk, New York, USA). Univariable analyses were performed with age ( $<25$ years vs. $\geq 25$ years), gender, BMI $\left(<25 \mathrm{~kg} / \mathrm{m}^{2} \mathrm{vs} . \geq 25 \mathrm{~kg} / \mathrm{m}^{2}\right)$, time from injury to primary ACLR ( $<12$ months vs. $\geq 12$ months), pre-injury Tegner activity level (high $\geq 6$ vs. low $<6$ ), graft type (HT vs. BPTB autograft), MM resection, MM repair, LM resection, LM repair, cartilage injury, 6-month quadriceps and hamstring strength and single-leg-hop test performance (LSI $\geq 90 \%$ vs. LSI $<90 \%$ ) as independent variables and contralateral ACLR as dependent variable. A multivariable logistic regression analysis was performed to evaluate independent risk factors for contralateral ACLR. Only variables attaining a $P$ value of $<0.2$ in the univariable analysis were entered in the multivariable analysis. The BMI was excluded from the multivariable model due to missing data. The results were reported as odds ratios (OR) with $95 \%$ confidence intervals (CI). The level of significance in all analyses was 5\% (two tailed).

\section{Results}

A total of 5393 patients who underwent primary ACLR were identified. A total of 252 patients (4.7\%) underwent contralateral ACLR during the 5-year follow-up. Patient characteristics for both the no-contralateral ACLR $(n=5141)$ and contralateral ACLR $(n=252)$ groups are summarised in Table 1.

\section{Univariable analyses}

Univariable logistic regression analyses revealed that older age ( $\geq 25$ years) (OR $0.30 ; 95 \%$ CI $0.23-0.41 ; P<0.001$ ), $\mathrm{BMI} \geq 25 \mathrm{~kg} / \mathrm{m}^{2}$ (OR $0.68 ; 95 \%$ CI $0.49-0.95 ; P=0.02$ ), time from injury to primary ACLR $>12$ months (OR 0.36 ; 95\% CI $0.25-0.52 ; P<0.001)$ and cartilage injury (OR $0.69 ; 95 \%$ CI $0.48-0.99 ; P=0.04)$ decreased the odds of contralateral ACLR, whereas female gender (OR 1.41; $95 \%$ CI 1.10-1.82; $P=0.007)$, pre-injury Tegner activity level $\geq 6$ (OR 2.90; 95\% CI 1.53-5.49; $P=0.001$ ), quadriceps strength LSI of $\geq 90 \%$ (OR 1.44; 95\% CI 1.10-1.90; $P=0.008$ ), hamstring strength LSI of $\geq 90 \%$ (OR 1.35 ; 95\% CI 1.03-1.76; $P=0.03$ ) and single-leg-hop test LSI of $\geq 90 \%$ (OR 1.96; 95\% CI 1.38-2.77; $P<0.001)$ increased the odds. No significant relationship was found between contralateral ACLR and graft type, MM and LM resection or repair (Table 1).

\section{Multivariable analysis}

Multivariable logistic regression analysis (included patients: 3,266 no-contralateral ACLR, 175 contralateral ACLR) revealed that older age ( $\geq 25$ years) (OR 0.40 ; 95\% CI $0.28-0.58 ; P<0.001)$ and time from injury to primary ACLR of $\geq 12$ months (OR 0.48 ; $95 \%$ CI $0.30-0.75$; $P=0.001)$ reduced the odds, whereas a 6-month singleleg-hop test LSI of $\geq 90 \%$ (OR 1.56 ; 95\% CI 1.04-2.34; $P=0.03$ ) increased the odds of contralateral ACLR. No significant relationships were found between contralateral ACLR and female gender, pre-injury Tegner activity level of $\geq 6$, HT autograft, MM repair, the presence of a cartilage injury and 6-month isokinetic quadriceps or hamstring strength LSI of $\geq 90 \%$ (Table 2).

\section{Discussion}

The most important finding in this study was that older age ( $\geq 25$ years) and delayed primary ACLR ( $\geq 12$ months) reduced the odds, whereas a symmetrical (LSI $\geq 90 \%$ ) 6-month single-leg-hop test increased the odds of 
Table 1 Patient characteristics and factors associated with the risk of contralateral ACLR in univariable analysis

\begin{tabular}{|c|c|c|c|c|}
\hline & $\begin{array}{l}\text { No contralateral ACLR } \\
(n=5141)\end{array}$ & $\begin{array}{l}\text { Contralateral ACLR } \\
(n=252)\end{array}$ & OR $(95 \% \mathrm{CI})$ & $P$ value \\
\hline \multicolumn{5}{|l|}{ Preoperative factors } \\
\hline Age at surgery, years, mean $\pm \mathrm{SD}$ & $28.7 \pm 10.5$ & $22.7 \pm 9.3$ & & \\
\hline Age $\geq 25$ years & $2864(55.7)$ & $70(27.8)$ & $0.30(0.23-0.41)$ & $<0.001 *$ \\
\hline Age $<25$ years & $2277(44.3)$ & $182(72.2)$ & & \\
\hline \multicolumn{5}{|l|}{ Gender } \\
\hline Female & $2249(43.7)$ & $132(52.4)$ & $1.41(1.10-1.82)$ & $0.007 *$ \\
\hline Male & $2892(56.3)$ & $120(47.6)$ & & \\
\hline $\mathrm{BMI}, \mathrm{kg} / \mathrm{m}^{2}$, mean $\pm \mathrm{SD}$ & $24.2 \pm 3.5$ & $23.7 \pm 3.1$ & & \\
\hline$\geq 25$ & $1108(29.2)$ & $47(21.9)$ & $0.68(0.49-0.95)$ & $0.02 *$ \\
\hline \multirow[t]{2}{*}{$<25$} & $2693(70.8)$ & $168(78.1)$ & & \\
\hline & $n=3801$ & $n=215$ & & \\
\hline Time from injury to surgery, months, mean \pm SD & $17.7 \pm 31.1$ & $8.2 \pm 13.9$ & & \\
\hline$\geq 12$ months & $1501(31.1)$ & $34(14.0)$ & $0.36(0.25-0.52)$ & $<0.001 *$ \\
\hline \multirow[t]{2}{*}{$<12$ months } & $3318(68.9)$ & $209(86.0)$ & & \\
\hline & $n=4819$ & $n=243$ & & \\
\hline Pre-injury Tegner activity level, median (range) & $7(1-10)$ & $8(2-10)$ & & \\
\hline High, $\geq 6$ & $4031(88.2)$ & $217(95.6)$ & $2.90(1.53-5.49)$ & $0.001 *$ \\
\hline \multirow[t]{2}{*}{ Low, $<6$} & $538(11.8)$ & $10(4.4)$ & & \\
\hline & $n=4569$ & $n=227$ & & \\
\hline \multicolumn{5}{|l|}{ Intraoperative factors } \\
\hline \multicolumn{5}{|l|}{ Graft type } \\
\hline HT autograft & $4719(91.8)$ & $239(94.8)$ & $1.18(0.98-1.43)$ & 0.08 \\
\hline BPTB autograft & $422(8.2)$ & $13(5.2)$ & & \\
\hline \multicolumn{5}{|l|}{ Medial meniscus surgery } \\
\hline Resection & $779(15.2)$ & $33(13.1)$ & $0.84(0.58-1.23)$ & 0.37 \\
\hline Repair & $284(5.5)$ & $20(7.9)$ & $1.47(0.92-2.36)$ & 0.10 \\
\hline \multicolumn{5}{|l|}{ Lateral meniscus surgery } \\
\hline Resection & $815(15.9)$ & $42(16.7)$ & $1.06(0.76-1.49)$ & 0.73 \\
\hline Repair & $179(3.5)$ & $12(4.8)$ & $1.39(0.76-2.52)$ & 0.28 \\
\hline \multicolumn{5}{|l|}{ Cartilage injury } \\
\hline Yes & $1026(20.0)$ & $37(14.7)$ & $0.69(0.48-0.99)$ & $0.04 *$ \\
\hline No & $4115(80.0)$ & $215(85.3)$ & & \\
\hline \multicolumn{5}{|l|}{ Postoperative factors (6 months) } \\
\hline Isokinetic quadriceps strength LSI, mean $\pm \mathrm{SD}$ & $84.6 \pm 16.2$ & $88.5 \pm 14.7$ & & \\
\hline$\geq 90 \%$ & $1495(33.8)$ & $95(42.4)$ & $1.44(1.10-1.90)$ & $0.008^{*}$ \\
\hline \multirow[t]{2}{*}{$<90 \%$} & $2931(66.2)$ & $129(57.6)$ & & \\
\hline & $n=4426$ & $n=224$ & & \\
\hline Isokinetic hamstring strength LSI, mean $\pm \mathrm{SD}$ & $90.0 \pm 19.7$ & $91.8 \pm 15.7$ & & \\
\hline$\geq 90 \%$ & $2001(45.3)$ & $118(52.7)$ & $1.35(1.03-1.76)$ & $0.03 *$ \\
\hline \multirow[t]{2}{*}{$<90 \%$} & $2419(54.7)$ & $106(47.3)$ & & \\
\hline & $n=4420$ & $n=224$ & & \\
\hline Single-leg-hop test LSI, mean \pm SD & $92.5 \pm 13.2$ & $96.1 \pm 9.5$ & & \\
\hline$\geq 90 \%$ & $2624(67.1)$ & $164(80.0)$ & $1.96(1.38-2.77)$ & $<0.001^{*}$ \\
\hline \multirow[t]{2}{*}{$<90 \%$} & $1284(32.9)$ & $41(20.0)$ & & \\
\hline & $n=3908$ & $n=205$ & & \\
\hline
\end{tabular}

Data are reported as $n(\%)$, unless otherwise indicated

$A C L R$ anterior cruciate ligament reconstruction, $B M I$ body mass index, $B P T B$ bone-patellar tendon-bone, $C I$ confidence intervals, $H T$ hamstring tendon, $L S I$ limb symmetry index, $O R$ odds ratio, $S D$ standard deviation

*Statistically significant $(P<0.05)$ 
Table 2 Factors associated with the risk of contralateral ACLR in multivariable logistic regression analysis

\begin{tabular}{llllc}
\hline & $\begin{array}{l}\text { Regression } \\
\text { coefficient } \\
(\beta)\end{array}$ & SE & OR (95\% CI) & $P$ value \\
& & & & \\
\hline Preoperative factors & -0.90 & 0.19 & $0.40(0.28-0.58)$ & $<0.001^{*}$ \\
Age $\geq 25$ years & 0.19 & 0.16 & $1.21(0.89-1.67)$ & 0.21 \\
Female gender & -0.73 & 0.23 & $0.47(0.30-0.75)$ & $0.001^{*}$ \\
Time from injury to surgery $\geq 12$ months & 0.60 & 0.39 & $1.83(0.84-3.99)$ & 0.12 \\
Pre-injury Tegner activity level $\geq 6$ & & & & 0.59 \\
Intraoperative factors & 0.19 & 0.36 & $1.21(0.59-2.45)$ & 0.59 \\
HT autograft & 0.16 & 0.30 & $1.17(0.64-2.13)$ & 0.92 \\
MM repair & -0.07 & 0.24 & $0.92(0.57-1.49)$ & \\
Cartilage injury & & & & 0.80 \\
Postoperative factors $(6$ months $)$ & 0.04 & 0.16 & $1.04(0.75-1.45)$ & 0.61 \\
Isokinetic quadriceps strength LSI $\geq 90 \%$ & 0.08 & 0.16 & $1.08(0.79-1.49)$ & $0.03 *$ \\
Isokinetic hamstring strength LSI $\geq 90 \%$ & 0.44 & 0.21 & $1.56(1.04-2.34)$ & \\
Single-leg-hop test LSI $\geq 90 \%$ &
\end{tabular}

$A C L R$ anterior cruciate ligament reconstruction, $C I$ confidence interval, $H T$ hamstring tendon, LSI limb symmetry index, $M M$ medial meniscus, $O R$ odds ratio, $S E$ standard error

*Statistically significant $(P<0.05)$ contralateral ACLR within 5 years of primary ACLR. In the entire cohort, the incidence of contralateral ACLR was $4.7 \%$ within 5 years of the index surgery.

In the literature, there is consistent evidence that younger age is an important risk factor for contralateral ACLR [2, 16, $17,23,31,36]$. Younger patients are more likely to return to high-risk activities, involving cutting/pivoting movements after an ACLR [5, 23, 30, 37], which could make them more prone to contralateral ACL injuries compared with their older counterparts [4, 18, 20]. Moreover, younger patients may tolerate less knee instability after a contralateral ACL injury and might be more willing to undergo a contralateral ACLR to continue participating in their pre-injury activities [23, 30]. In line with previous literature, a reduced odd of contralateral ACLR was found in older (age $\geq 25$ years) patients.

In the present study, female gender did not affect the risk of contralateral ACLR in the multivariable regression model, meaning that gender is probably not associated per se with contralateral ACLR. These results are supported by those of the large cohort registry studies by Andernord et al. [2], Wasserstein et al. [36] and Gallo et al. [16], which found that patient gender was not a predictor of contralateral ACLR. In contrast, the large cohort registry studies by Maletis et al. [23] and Snaebjornsson et al. [31] reported female gender as a factor associated with an increased risk of contralateral ACLR. Taken together, these results lead us to conclude that, to date, there is no definitive association between female gender and the risk of contralateral ACLR.

One poorly investigated risk factor for contralateral ACLR is the delay of primary ACLR. Andernord et al. [2] reported that, in female patients, an index ACLR performed within 6 months of the injury was a predictor of contralateral ACLR. Similarly, Fältström et al. [14] found that an early ACLR ( $<3$ months from injury to surgery) was a predictor of contralateral ACLR. However, although the results of both studies were adjusted for age, they did not take account of the patient's preinjury activity level. The authors [2, 14] suggested that, since an early ACLR in Sweden is predominantly performed on individuals with high preinjury activity levels, the injury to surgery interval was probably a proxy measurement of the patient's activity level.

In the current study, a pre-injury Tegner activity level $\geq 6$ increased the odds of having a contralateral ACLR in the univariable analysis. However, the multivariable regression model did not show any relationship between pre-injury activity level and contralateral ACLR. Conversely, delayed primary ACLR ( $\geq 12$ months) decreased the risk of having contralateral ACLR. It has previously been hypothesised $[1,6,32]$ that patients with delayed primary ACLR may adapt to the injured knee, thereby having less risk to expose their operated knee to re-injuries and revision ACLR. The same consideration could be applied for the risk of contralateral ACL injury and reconstruction. Moreover, as reported for revision ACLR [1, 6], another hypothesis may be that patients undergoing early primary ACLR would be more willing to undergo also early contralateral ACLR to continue performing their pre-injury activities. This would then bias the results indicating lower risk of contralateral ACLR in case of delayed primary ACLR.

In this study, no correlation was found between cartilage injury and repair or resection of the MM or LM at the time of the primary ACLR and the occurrence of contralateral ACLR. These results are in line with those of previous 
studies showing that neither meniscus nor cartilage injuries $[2,29]$ or meniscus procedures $[4,36]$ performed at the primary ACLR affect the risk of contralateral ACL injury or reconstruction.

There is still controversy about the effect of graft choice at primary ACLR as a possible risk factor for contralateral ACL injury or reconstruction. Conflicting results have been reported in both RCTs and registry studies. In an RCT based on 330 patients with a minimum 2-year followup, Mohtadi et al. [24] found no differences in the rate of contralateral ACL injury between patients with HT or BPTB autografts. On the other hand, in an RCT based on 90 patients with a 15-year follow-up, Leys et al. [20] reported that the use of a BPTB autograft rather than an HT autograft was associated with 2.6 times higher odds of contralateral ACL injury. In a large cohort study based on the Swedish national knee ligament registry, Andernord et al. [2] showed that the choice between an HT or a BPTB autograft at the primary ACLR did not affect the risk of contralateral ACLR at a 5-year follow-up. In contrast, in a recent study based on the New Zealand ACL registry, Rahardja et al. [27] reported that patients with a BPTB autograft at the primary ACLR ran a 1.9 times higher risk of undergoing a contralateral ACLR compared with patients with an HT autograft. The authors included several variables in their Cox proportional hazard regression analysis. Adjustments were made for age, gender, time from injury to primary ACLR, activity at the time of injury, meniscus treatment and preoperative Marx activity score. In the present study, neither the univariable nor the multivariable logistic regression analysis (including age, gender, time from injury to primary ACLR, pre-injury Tegner activity level, MM repair, cartilage injury, 6-month isokinetic quadriceps and hamstring strength and singleleg-hop test performance) revealed any significant association between graft choice and the risk of undergoing contralateral ACLR, suggesting that the graft at primary ACLR is probably not associated per se with the incidence of contralateral ACLR. To date, based on these conflicting results, it is difficult to draw any definitive conclusion regarding the relationship between graft choice at primary ACLR and the risk of contralateral ACLR.

The significant association between symmetrical (LSI of $\geq 90 \%$ ) isokinetic quadriceps or hamstring strength 6 months after the index surgery (primary ACLR) and contralateral ACLR in the univariable analysis was not present in the multivariable analysis. A recent large cohort study [9] showed that older age reduced the odds of achieving symmetrical isokinetic quadriceps and hamstring strength 6 months after primary ACLR. Older age ( $\geq 25$ years) resulted to be the factor that most affected the risk of contralateral ACLR in the multivariable analysis. This may suggest that the results of these tests probably do not have an important effect on the risk of contralateral ACLR, whereas age at the time of primary ACLR is a significant risk factor.

One interesting result was that a symmetrical (LSI $\geq 90 \%$ ) single-leg-hop test performance 6 months after the index surgery (primary ACLR) was a factor that independently affected the risk of contralateral ACLR. Single-leg-hop tests are commonly used to assess confidence in the limb, neuromuscular control and the ability to tolerate loads related to sport activities [21]. It has been shown that hop tests 6 months after ACLR are able to predict return to sport participation at the preinjury activity level [25]. It might be hypothesised that patients who achieved a single-leg-hop test LSI of $\geq 90 \%$ may have returned to their preinjury activity level to a greater extent compared with patients with an LSI of $<90 \%$. This may have exposed their contralateral knee to a higher risk of ACL injury and subsequent ACLR.

The major strength of the current study was the large cohort included (5393 patients). Moreover, there was a large $(n=252)$ number of patients with contralateral ACLR. This allowed a comprehensive evaluation of several (preoperative, intraoperative and postoperative) risk factors for contralateral ACLR and gave the opportunity to conduct a robust multivariable logistic regression analysis. The latter is a crucial aspect when it comes to simultaneously and independently evaluating several potential risk factors for the outcome, as there might be an overlap between the factors investigated in the univariable analysis and it is essential to determine the relative importance of one factor over another. The large number and heterogeneity of the included patients give the results high external validity. Finally, another strength was that, in contrast to previous large cohort studies based on national registries, patients underwent ACLR and were assessed at the same clinic 6 months postoperatively. In addition, rehabilitation and recommendations for return to sport or preinjury activities were standardised.

There are some limitations to consider. The outcome of this study was contralateral ACLR and not contralateral ACL injury. Probably, not all patients with a contralateral ACL injury undergo ACLR. The number of contralateral ACLRs is therefore probably lower than that of contralateral ACL injuries and the risk factors for contralateral ACLR might differ from those for contralateral ACL injury. However, as reported by Andernord et al. [2], it is also important to consider that contralateral ACLR might be a more accurate measurement of the clinically disabling condition compared with contralateral ACL injury, as it might represent the proportion of patients who are not able to cope with their ACL-deficient knee. Missing data for some of our risk factors was also a limitation. The BMI (which was associated with a contralateral ACLR in the univariable analysis) had the highest proportion of missing values, which prevented its inclusion in the multivariable logistic regression analysis. These factors may have had an effect on the results. 
However, this limitation is probably reduced by the large cohort studied and the inclusion of many, different potential risk factors for contralateral ACLR. Finally, data on other factors which may potentially influence the risk of contralateral ACLR, such as activity level after the index surgery (primary ACLR) and return to sport, were not available and could therefore not be included in the analysis.

\section{Conclusion}

Older age ( $\geq 25$ years) and delayed primary ACLR $(\geq 12$ months) reduced the odds, whereas a symmetrical (LSI $\geq 90 \%$ ) 6-month single-leg-hop test increased the odds of contralateral ACLR within 5 years of primary ACLR. Knowledge of the factors affecting the risk of contralateral ACLR is important when it comes to the appropriate counselling for primary ACLR. Patients should be advised regarding factors affecting the risk of contralateral ACLR.

Funding Open access funding provided by Karolinska Institute.

\section{Declarations}

Conflict of interest The authors declare that they have no conflict of interest.

Ethical approval Ethical approval for this study was obtained from the regional ethics committee, Karolinska Institutet, Diarienumber 2016/1613-31/2.

Open Access This article is licensed under a Creative Commons Attribution 4.0 International License, which permits use, sharing, adaptation, distribution and reproduction in any medium or format, as long as you give appropriate credit to the original author(s) and the source, provide a link to the Creative Commons licence, and indicate if changes were made. The images or other third party material in this article are included in the article's Creative Commons licence, unless indicated otherwise in a credit line to the material. If material is not included in the article's Creative Commons licence and your intended use is not permitted by statutory regulation or exceeds the permitted use, you will need to obtain permission directly from the copyright holder. To view a copy of this licence, visit http://creativecommons.org/licenses/by/4.0/.

\section{References}

1. Andernord D, Björnsson H, Petzold M, Eriksson BI, Forssblad M, Karlsson J, Samuelsson K (2014) Surgical predictors of early revision surgery after anterior cruciate ligament reconstruction: results from the Swedish national ligament register on 13,102 patients. Am J Sports Med 42(7):1574-1582

2. Andernord D, Desai N, Bjornsson H, Gillen S, Karlsson J, Samuelsson K (2015) Predictors of contralateral anterior cruciate ligament reconstruction: a cohort study of 9061 patients with 5-year follow-up. Am J Sports Med 43(2):295-302
3. Barber-Westin SD, Noyes FR (2011) Objective criteria for return to athletics after anterior cruciate ligament reconstruction and subsequent reinjury rates: a systematic review. Phys Sports Med 39(3):100-110

4. Bourke HE, Salmon LJ, Waller A, Patterson V, Pinczewski LA (2012) Survival of the anterior cruciate ligament graft and the contralateral ACL at a minimum of 15 years. Am J Sports Med 40(9): 1985-1992

5. Brophy RH, Schmitz L, Wright RW et al (2012) Return to play and future ACL injury risk after ACL reconstruction in soccer athletes from the Multicenter Orthopaedic Outcomes Network (MOON) group. Am J Sports Med 40(11):2517-2522

6. Cristiani R, Forssblad M, Edman G, Eriksson K, Stålman A (2021) Age, time from injury to surgery and quadriceps strength affect the risk of revision surgery after primary ACL reconstruction. Knee Surg Sports Traumatol Arthrosc. https://doi.org/10. 1007/s00167-021-06517-8

7. Cristiani R, Forssblad M, Engström B, Edman G, Stålman A (2018) Risk factors for abnormal knee laxity after primary anterior cruciate ligament reconstruction. Arthroscopy 34(8):2478-2484

8. Cristiani R, Mikkelsen C, Edman G, Forssblad M, Engström B, Stålman A (2020) Age, gender, quadriceps strength and hop test performance are the most important factors affecting the achievement of a patient-acceptable symptom state after ACL reconstruction. Knee Surg Sports Traumatol Arthrosc 28(2):369-380

9. Cristiani R, Mikkelsen C, Forssblad M, Engström B, Stålman A (2019) Only one patient out of five achieves symmetrical knee function 6 months after primary anterior cruciate ligament reconstruction. Knee Surg Sports Traumatol Arthrosc 27(11):3461-3470

10 Cristiani R, Mikkelsen C, Wange $\mathrm{P}$, Olsson D, Stålman A, Engström B (2020) Autograft type affects muscle strength and hop performance after ACL reconstruction. A randomised controlled trial comparing patellar tendon and hamstring tendon autografts with standard or accelerated rehabilitation. Knee Surg Sports Traumatol Arthrosc. https://doi.org/10.1007/ s00167-020-06334-5

11. Cristiani R, Sarakatsianos V, Engström B, Samuelsson K, Forssblad M, Stålman A (2019) Increased knee laxity with hamstring tendon autograft compared to patellar tendon autograft: a cohort study of 5462 patients with primary anterior cruciate ligament reconstruction. Knee Surg Sports Traumatol Arthrosc 27(2):381-388

12. Cristiani R, Viheriävaara S, Janarv PM, Edman G, Forssblad M, Stålman A (2021) Knee laxity and functional knee outcome after contralateral ACLR are comparable to those after primary ACLR. Knee Surg Sports Traumatol Arthrosc. https://doi.org/10.1007/ s00167-020-06417-3

13. Cronstrom A, Tengman E, Hager CK (2021) Risk factors for contra-lateral secondary anterior cruciate ligament injury: a systematic revies with meta-analysis. Sports Med. https://doi.org/10. 1007/s40279-020-01424-3

14. Fältström A, Hägglund M, Magnusson H, Forssblad M, Kvist J (2016) Predictors for additional anterior cruciate ligament reconstruction: data from the Swedish national ACL register. Knee Surg Sports Traumatol Arthrosc 24(3):885-894

15. Freedman KB, D'Amato MJ, Nedeff DD, Kaz A, Bach BR Jr, (2003) Arthroscopic anterior cruciate ligament reconstruction: a meta-analysis comparing patellar tendon and hamstring tendon autografts. Am J Sports Med 31(1):2-11

16. Gallo MC, Bolia IK, Jalali O, Rosario S, Rounds A, Heidari KS, Trasolini NS, Prodromo JP, Hatch GF, Weber AE (2020) Risk factors for early subsequent (revision or contralateral) ACL reconstruction: a retrospective database study. Orthop J Sports Med 8(2):232596711901173 
17. Hettrich CM, Dunn WR, Reinke EK, Spindler KP (2013) The rate of subsequent surgery and predictors after anterior cruciate ligament reconstruction: two- and 6-year follow-up results from a multicenter cohort. Am J Sports Med 41(7):1534-1540

18. Hui C, Salmon LJ, Kok A, Maeno S, Linklater J, Pinczewski LA (2011) Fifteen-year outcome of endoscopic anterior cruciate ligament reconstruction with patellar tendon autograft for "isolated" anterior cruciate ligament tear. Am J Sports Med 39(1):89-98

19. Kvist J, Kartus J, Karlsson J, Forssblad M (2014) Results from the Swedish national anterior cruciate ligament register. Arthroscopy 30(7):803-810

20. Leys T, Salmon L, Waller A, Linklater J, Pinczewski L (2012) Clinical results and risk factors for reinjury 15 years after anterior cruciate ligament reconstruction: a prospective study of hamstring and patellar tendon grafts. Am J Sports Med 40(3):595-605

21. Logerstedt D, Grindem H, Lynch A, Eitzen I, Engebretsen L, Risberg MA, Axe MJ, Snyder-Mackler L (2012) Single-legged hop tests as predictors of self-reported knee function after anterior cruciate ligament reconstruction: the Delaware-Oslo ACL cohort study. Am J Sports Med 40(10):2348-2356

22. Lunde AS, Lundeborg S, Lettenstrom GS, Thygesen L, Huebner J (1980) The person-number system of Sweden, Norway, Denmark, and Israel. Vital Health Stat 2(84):1-59

23. Maletis GB, Inacio MC, Funahashi TT (2015) Risk factors associated with revision and contralateral anterior cruciate ligament reconstructions in the Kaiser Permanente ACLR registry. Am J Sports Med 43(3):641-647

24. Mohtadi N, Chan D, Barber R, Paolucci EO (2016) Reruptures, reinjuries, and revisions at a minimum 2-year follow-up. Clin $\mathrm{J}$ Sport Med 26(2):96-107

25. Nawasreh Z, Logerstedt D, Cummer K, Axe M, Risberg MA, Snyder-Mackler L (2018) Functional performance 6 months after ACL reconstruction can predict return to participation in the same preinjury activity level 12 and 24 months after surgery. Br J Sports Med 52(6):375

26. Paterno MV, Schmitt LC, Ford KR, Rauh MJ, Myer GD, Huang B, Hewett TE (2010) Biomechanical measures during landing and postural stability predict second anterior cruciate ligament injury after anterior cruciate ligament reconstruction and return to sport. Am J Sports Med 38(10):1968-1978

27. Rahardja R, Zhu M, Love H, Clatworthy MG, Monk AP, Young SW (2020) Effect of graft choice on revision and contralateral anterior cruciate ligament reconstruction: results from the New Zealand ACL Registry. Am J Sports Med 48(1):63-69

28. Rothrauff BB, Karlsson J, Musahl V, Irrgang JJ, Fu FH (2020) ACL consensus on treatment, outcome, and return to sport. Knee Surg Sports Traumatol Arthrosc 28(8):2387-2389

29. Salmon L, Russell V, Musgrove T, Pinczewski L, Refshauge $\mathrm{K}$ (2005) Incidence and risk factors for graft rupture and contralateral rupture after anterior cruciate ligament reconstruction. Arthroscopy 21(8):948-957

30. Shelbourne KD, Gray T, Haro M (2009) Incidence of subsequent injury to either knee within 5 years after anterior cruciate ligament reconstruction with patellar tendon autograft. Am J Sports Med 37(2):246-251

31. Snaebjornsson T, Hamrin Senorski E, Sundemo D, Svantesson E, Westin O, Musahl V, Alentorn-Geli E, Samuelsson K (2017) Adolescents and female patients are at increased risk for contralateral anterior cruciate ligament reconstruction: a cohort study from the Swedish National Knee Ligament Register based on 17,682 patients. Knee Surg Sports Traumatol Arthrosc 25(12):3938-3944

32. Snaebjörnsson T, Hamrin-Senorski E, Svantesson E, Westin O, Persson A, Karlsson J, Samuelsson K (2019) Graft fixation and timing of surgery are predictors of early anterior cruciate ligament revision: a cohort study from the Swedish and Norwegian knee ligament registries based on 18,425 patients. JBJS Open Access 4:e0037

33. Tegner Y, Lysholm J (1985) Rating systems in the evaluation of knee ligaments injuries. Clin Orthop Relat Res 198:43-49

34. The Swedish National Knee Ligament Registry. http://www.aclre gister.nu

35. Thomeé R, Kaplan Y, Kvist J, Myklebust G, Risberg MA, Theisen D, Tsepis E, Werner S, Wondrasch B, Witvrouw E (2011) Muscle strength and hop performance criteria prior to return to sports after ACL reconstruction. Knee Surg Sports Traumatol Arthrosc 19(11):1798-1805

36. Wasserstein D, Khoshbin A, Dwyer T, Chahal J, Gandhi R, Mahomed N, Ogilvie-Harris D (2013) Risk factors for recurrent anterior cruciate ligament reconstruction: a population study in Ontario, Canada, with 5-year follow-up. Am J Sports Med 41(9):2099-2107

37. Webster KE, Feller JA (2016) Exploring the high reinjury rate in younger patients undergoing anterior cruciate ligament reconstruction. Am J Sports Med 44(11):2827-2832

38. World Health Organization (2000) Obesity: Preventing and managing the global epidemic. World Health Organization, Geneva

39. Wright RW, Magnussen RA, Dunn WR, Spindler KP (2011) Ipsilateral graft and contralateral ACL rupture at five years or more following ACL reconstruction: a systematic review. J Bone Joint Surg Am 93(12):1159-1165

Publisher's Note Springer Nature remains neutral with regard to jurisdictional claims in published maps and institutional affiliations. 